\title{
A serum mesothelin level is a prognostic indicator for patients with malignant mesothelioma in routine clinical practice
}

Mark Linch ${ }^{\dagger}$, Spyridon Gennatas`, Stanislav Kazikin, Jhangir lqbal, Ranga Gunapala, Kathryn Priest, Joanne Severn, Alison Norton, Bee Ayite, Jaishree Bhosle, Mary O'Brien and Sanjay Popat*

\begin{abstract}
Background: Malignant mesothelioma (MM) carries a poor prognosis and response rates to palliative chemotherapy remain low. Identifying patients with MM that are unlikely to respond to chemotherapy could prevent futile treatments and improve patient quality of life. Studies have suggested that soluble mesothelin is a potential biomarker for early diagnosis and prognosis of $\mathrm{MM}$. We set out to explore the utility of serum mesothelin in routine clinical practice.
\end{abstract}

Methods: We conducted a prospective exploratory study of serum mesothelin levels in 53 consecutive patients with MM at our institution between April 2009 and February 2011. Survival was assessed and analysed by mesothelin level as both continuous and categorical variables using Cox regression models. Differences in response rate between treatment groups were assessed by the Kruskal-Wallis Test.

Results: All 53 patients, who had been given study information agreed to participate. The patients' median age was 69 (range 24-90). Median mesothelin level was $2.7 \mathrm{nM}$ and this value was used to dichotomize categories: $\leq 2.7 \mathrm{nM}$ (low) and $>2.7 \mathrm{nM}$ (high). The progression free survival (PFS) for low vs high mesothelin was 8.0 vs 5.1 months (HR 1.8, p-0.058). When mesothelin was accessed as a continuous variable for PFS the HR was 1.03 (95\% Cl: $1.01-1.06 ; p=0.013)$. The overall survival (OS) for low vs high mesothelin was 17.2 vs 11.3 months ( $H R$ 1.9, $p=0.088)$. When mesothelin was assessed as a continuous variable for OS the HR was 1.02 (95\% Cl: $0.99-1.04$; $p=0.073)$. Thirty patients received chemotherapy of which 18 had a pre-chemotherapy serum mesothelin level. In these 18 patients, the pre-chemotherapy mesothelin level did not correlate with response.

Conclusions: A single random sample provides information about patient prognosis but does not predict treatment response. We suggest further prospective validation of mesothelin testing as a prognostic biomarker.

Keywords: Biomarker, Mesothelin, Prognosis, Response

\section{Background}

Malignant mesothelioma (MM) is an aggressive cancer of serosal surfaces such as the pleura, peritoneum and rarely the pericardium. It is causally linked to asbestos exposure with a lag time of 15-60 years and has an incidence of approximately 2500 cases/year in the UK [1]. Diagnosis of MM is challenging as symptoms and early radiographic signs are often non-specific and their significance can be masked by multiple co-morbidities of

\footnotetext{
* Correspondence: Sanjay.Popat@rmh.nhs.uk

${ }^{\dagger}$ Equal contributors

Royal Marsden Hospital, Fulham Road, SW3 6JJ London, Surrey, UK
}

this normally older patient. Typically, histological features of MM include positive immunohistochemical staining for epithelial membrane antigen, WT1, cytokeratin 5/6 and HBME-1 [2]. Expression of several proteins detected by immunochemistry have been suggested to correlate with survival such as IL4R $\alpha$ [3], c-MET [4], aquaporin1 [5], calretinin [6], and HtrA1 [7]. The optimal surgical approach is debated and includes palliative support with or without chemotherapy contingent on co-morbidities.

The identification of a robust serological biomarker for mesothelioma could have a significant impact in this 
disease in helping with early diagnosis, avoiding multiple invasive procedures, providing prognostic and/or predictive information and aid in treatment response assessment. The latter is particularly important, since the response evaluation criteria in sold tumours (RECIST) and the modified RECIST criteria for mesothelioma are associated with significant variability $[8,9]$. Several candidates have shown promise as predictive/prognostic biomarkers such as LDH [10], C-Reactive Protein (CRP) levels ( $\geq 1 \mathrm{mg} / \mathrm{dL}$, predicting a poorer outcome) [11], neutrophil/lymphocyte ratio [6], platelet count $(>400,000 / \mathrm{microL}$, predicting a poorer outcome) [12], osteopontin [13], and fibulin-3 [14]. However, the most extensively studied is mesothelin, which has been shown to potentially differentiate between mesothelioma and other conditions, both benign and malignant [2,15-17], and also potentially correlates with response to therapy [18]. Mesothelin is a $40 \mathrm{kDa}$ membrane-localised protein that along with the $31 \mathrm{kDa}$ megakaryocyte potentiation factor (MPF) are cleavage products of a $69 \mathrm{kDa}$ precursor protein encoded by MSLN on chromosome 16. Mesothelin is proposed to play a role in cell adhesion as it binds to the cell adhesion molecule Ca125 (Muc16) and forced over-expression of MSLN in NIH3T3 cells leads to increased adhesion to a plastic substrate. In tissue culture, mesothelin also promotes ERK dependent proliferation [19], apoptosis resistance, anoikis resistance and invasion [20]. Mesothelin may therefore be involved in cancer metastasis and its role as a potential therapeutic target is being actively pursued [21]. It is predominantly expressed in epithelioid subtype mesotheliomas, with little/no expression in sarcomatoid sub-types. MPF and mesothelin isoforms 1 and 3 can be detected as soluble proteins in plasma or serum, which may be detected using a validated commercial dual antibody ELISA platform [16]. Mesothelin level seems to correlate with MM disease bulk and can potentially predict relapse in patients who had previously resected mesothelioma [22]. Additionally, several studies have provided some evidence for an association between high mesothelin level and poorer survival $[13,15,23]$. While the absolute baseline serum mesothelin level has not been reported to predict for treatment response a number of trials have demonstrated that a fall in the mesothelin level with treatment correlates well with radiological response rate and overall survival [24,25].

We therefore conducted this exploratory study of serum mesothelin testing in patients with MM in routine clinical practice.

\section{Methods}

The study was designed and submitted as a Service Evaluation. As such it fell under the remit of the Royal Marsden Hospital's Audit Committee, which approved it without the need for a separate ethics committee approval.

\section{Patients}

We identified patients attending our Cancer Centre with a histologically confirmed diagnosis of malignant mesothelioma.

\section{Mesothelin assay}

The serum mesothelin assay was performed in a single laboratory. Serum samples were prospectively collected in prevalent MM cases alongside clinical data, contemporaneous to on-going patient treatment and follow-up. Levels of serum mesothelin (referred to hereafter as mesothelin) were assayed with a commercial ELISA kit (Mesomark ${ }^{\text {TM }}$ Fujirebio Diagnostics, Malvern PA) according to the manufacturer's instructions. Results were expressed in nanomoles per litre (nmol/L). This commercially available kit has passed FDA (US Food and Drug Administration) quality assurance standards. All analyses were performed in a batch, blinded to clinical outcomes.

\section{Treatments}

Patients were treated as per local standard of care. Surgery for mesothelioma (e.g. radical pleurectomy or extrapleural pneumonectomy) was not routine practice at the time of this study. Patients that received chemotherapy were offered treatment as per the standard institutional guidelines that included research protocols. At the time of this study treatment regimens included cisplatin/pemetrexed, cisplatin/bortezomib, mitomycin/vinblastine/cisplatin and cisplatin/raltitrexed. To be eligible for anti-cancer systemic therapy, patients were required to have an Eastern Cooperative Oncology Group (ECOG) performance status $\leq 2$ (as per local policy), have adequate renal function (clearance $>60 \mathrm{ml} / \mathrm{min}$ ), normal haematological indices and no serious co-morbidities, as per local guidelines. Patients underwent pre-treatment physical examination and computed tomography (CT) scan of the thorax and abdomen, as per routine clinical care.

\section{Response}

Response was evaluated radiologically. CT scans of the thorax and abdomen were performed at baseline and following every 2 cycles of chemotherapy, as per local policy. Objective radiological response was assessed according to RECIST criteria [9]. The overall response rate (ORR) was calculated as the proportion of patients achieving a complete remission (CR) or partial remission (PR).

\section{Statistics}

For the purposes of this study the progression free survival (PFS) was calculated from date of mesothelin measurement to disease progression or death, otherwise censored at the last follow-up date. Overall survival (OS) was calculated from the date of mesothelin measurement to death, or else censored at the last follow-up date. Survival curves 
Table 1 Patient characteristics

\begin{tabular}{|c|c|c|c|}
\hline Variable & Categories & & $\begin{array}{c}\text { Number of } \\
\text { patients }(\%)^{*}\end{array}$ \\
\hline Patients in study & & & $53(100)$ \\
\hline \multirow[t]{4}{*}{ Mesothelioma subtype } & Epitheloid & & $46(87)$ \\
\hline & Sarcomatoid & & $1(2)$ \\
\hline & Biphasic & & $5(9)$ \\
\hline & Unknown & & $1(2)$ \\
\hline \multirow[t]{2}{*}{ Sex } & Male & & $36(68)$ \\
\hline & Female & & $17(32)$ \\
\hline Age & Mean & & 69 (range 24-90) \\
\hline \multirow[t]{5}{*}{ Performance status } & 0 & & $4(8)$ \\
\hline & 1 & & $28(53)$ \\
\hline & 2 & & $6(11)$ \\
\hline & 3 & & $2(4)$ \\
\hline & Unknown & & $13(25)$ \\
\hline \multirow{4}{*}{$\begin{array}{l}\text { Chemotherapy lines } \\
\text { including current }\end{array}$} & 0 & & $14(26)$ \\
\hline & 1 & & $36(68)$ \\
\hline & 2 & & $2(4)$ \\
\hline & 3 & & $1(2)$ \\
\hline \multirow{4}{*}{$\begin{array}{l}\text { Chemotherapy status } \\
\text { while on the study }\end{array}$} & Given & & $30(56.6)$ \\
\hline & & $\begin{array}{l}\text { Mesomark } \\
\text { prior to } C T\end{array}$ & $12(40)$ \\
\hline & & $\begin{array}{l}\text { Mesomark } \\
\text { post CT }\end{array}$ & $18(60)$ \\
\hline & Not given & & $23(43)$ \\
\hline
\end{tabular}

*Percentages rounded up to the nearest 1.0\%; Mesomark, serum mesothelin ELISA test; CT, chemotherapy. were generated using the Kaplan-Meier method. Survival was analysed for mesothelin as both continuous and categorical variables using Cox regression models. For the categorical assessment, the two groups were assigned as above or below and equal to the median value. The choice of median was made prior to analysis given the small number of patients and the presence of outlying measurements on both sides of the spectrum. Any differences in pre-chemotherapy mesothelin and treatment response were assessed by Kruskal-Wallis Test and Dunn's multiple comparison test was performed. Outcomes were not assessed by chemotherapy regime given the small numbers.

\section{Results}

\section{Patient characteristics}

Between April 2009 and February 201153 patients with malignant mesothelioma underwent random mesothelin level testing. The mean age was 69 years (range 24-90 years) and over $60 \%$ of patients had an ECOG performance status of $0-1$ at the time of mesothelin testing. On histological assessment, 46 (87\%) patients had epitheloid MM, 1 (2\%) patient had sarcomatoid MM, 5 patients (9\%) had biphasic MM and the subtype was unknown in 1 patient (2\%). Forty-nine (92\%) patients had pleural MM and 4 (8\%) patients had peritoneal mesothelioma. There was a male predominance with 36 men and 17 women (ratio 2.1:1).

Thirty out of 53 patients received chemotherapy during their management for MM and 18/30 patients had their mesothelin level tested in the month prior to starting chemotherapy. Patient characteristics are summarised in Table 1.

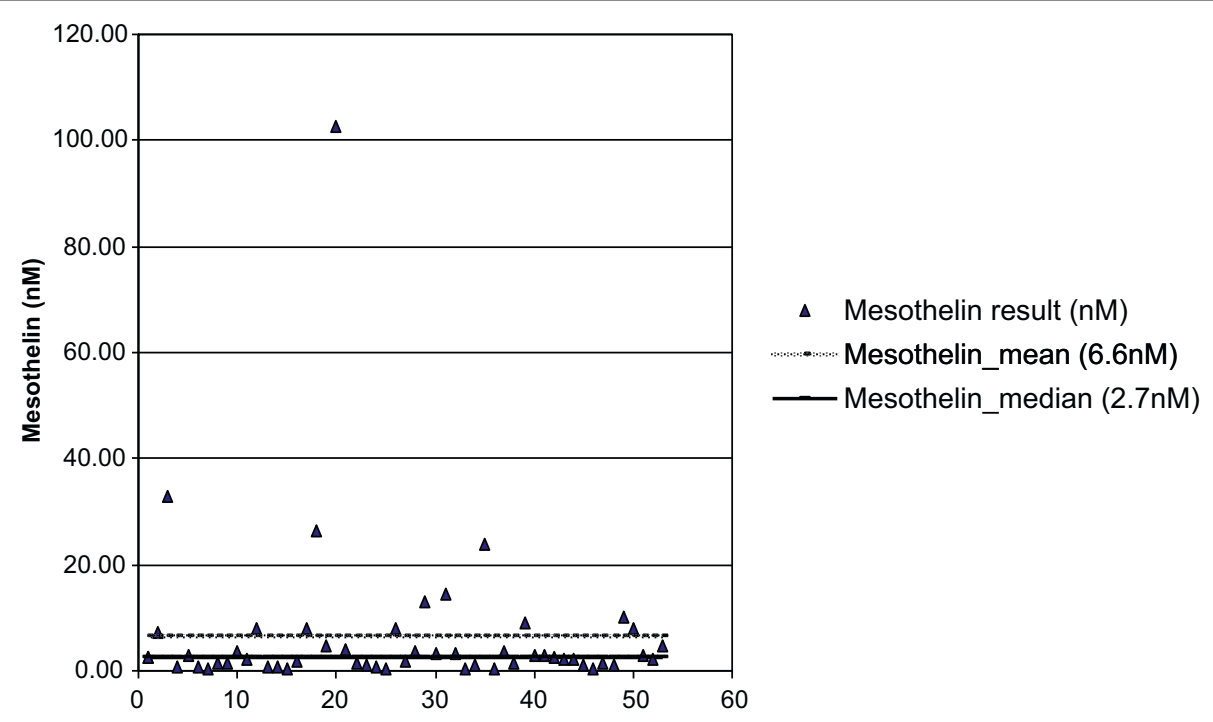

Figure 1 Scatter plot of mesothelin level of study participants. 


\section{Random mesothelin levels}

In the 53 patients tested for serum mesothelin the mean level was $6.6 \mathrm{nM}$ (range 0.3-102.5 $\mathrm{nM}$ ). The value of $102.5 \mathrm{nM}$ appeared to be an outlier and the median was calculated at $2.7 \mathrm{nM}$; the median value was chosen a priori and used for subsequent analyses (Figure 1).

\section{Progression Free Survival (PFS)}

Of the 53 patients, 46 (87\%) progressed and 7 (13\%) were censored. When analysed as a continuous variable the Hazard Ratio (HR) for mesothelin was 1.03 (95\% CI: 1.01 - 1.06; $\mathrm{p}=0.013$ ); for each unit increase in mesothelin the hazard of progression increased by $3 \%$. The median PFS was 7.0 months (95\% CI: 4.7 - 9.2 months) and the median follow-up for censored patients was 18.1 months (Figure 2A).
When mesothelin was analysed as a categorical variable (>2.7 $\mathrm{nM}$ vs $\leq 2.7 \mathrm{nM}$ ) the HR was 1.8 (95\% CI: $0.9-3.2$ ); $\mathrm{p}=0.059$ ). This translated to a median of 8.0 months (95\% CI: 3.9 - 12.0 months) for mesothelin levels $\leq$ $2.7 \mathrm{nM}$ and a median of 5.1 months (95\% CI: 2.3 7.8 months) for mesothelin levels $>2.7 \mathrm{nM}$. The median follow-up for censored patients was 14.9 months in the $\leq 2.7$ (nM) group and 23.8 months in the $>2.7$ (nM) group (Figure 2B).

\section{Overall Survival (OS)}

Of the 53 patients assessed, 29 (55\%) died and 24 (45\%) were censored. When analysed as a continuous variable the Hazard Ratio (HR) for mesothelin was 1.02 (95\% CI: 0.99 - 1.04; $\mathrm{p}=0.073)$; for each unit-increase in mesothelin the hazard of death increased by $2 \%$. The median

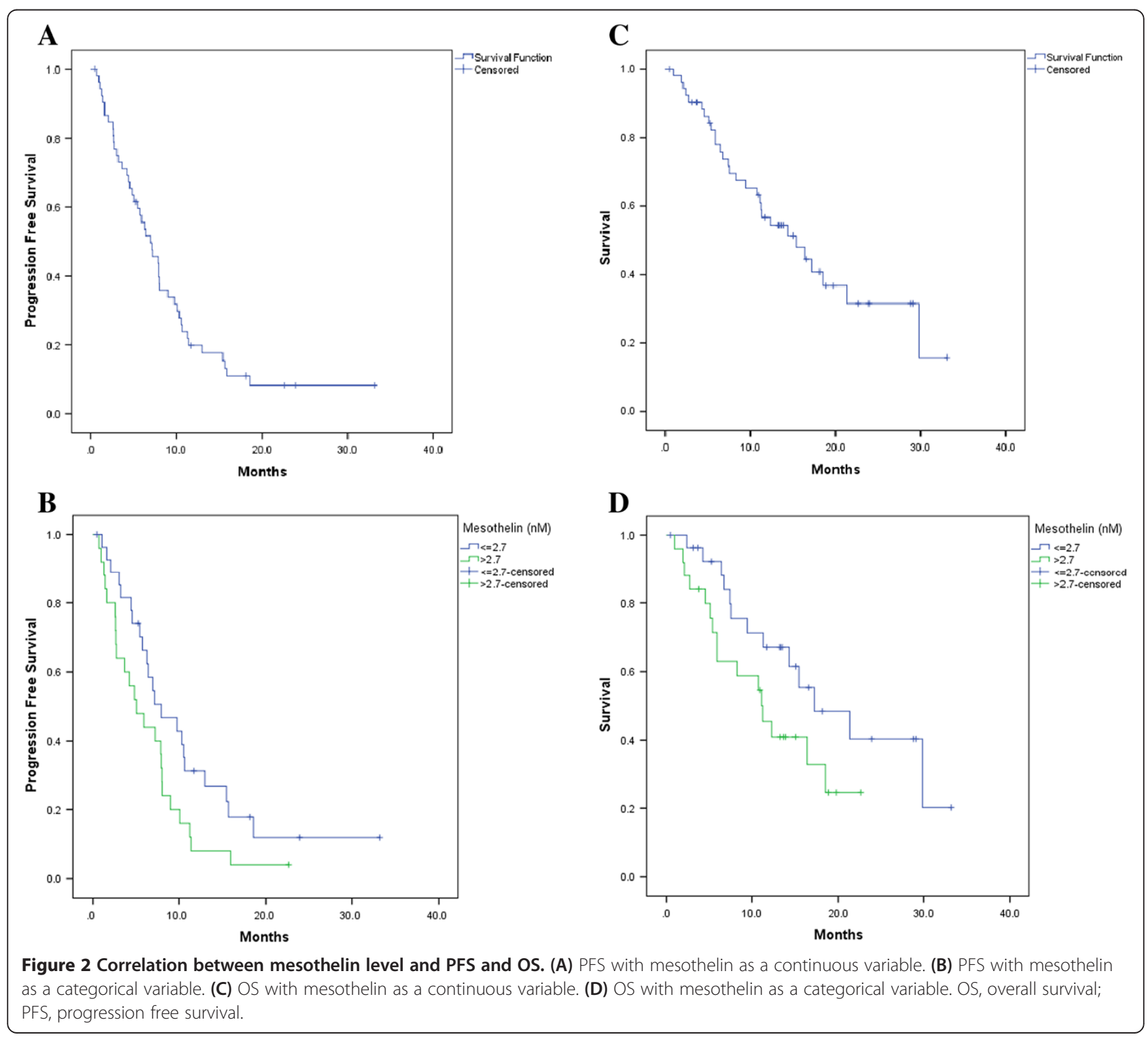


survival was 15.4 months (95\% CI: 9.2 - 21.6 months) and the median follow-up time for censored patients was 13.8 months (Figure 2C).

When mesothelin was analysed as a categorical variable (>2.7 $\mathrm{nM}$ vs $\leq 2.7 \mathrm{nM}$ ) the HR was 1.9 (95\% CI: 0.9 - 4.1); $\mathrm{p}=0.088)$. This translated to a median OS of 17.2 months (95\% CI: 8.2 - 26.2 months for mesothelin levels $\leq 2.7 \mathrm{nM}$ and 11.3 months (95\% CI: 6.7 - 15.8 months) for mesothelin levels of $>2.7 \mathrm{nM}$. The median follow-up for censored patients was 13.6 months in the $\leq 2.7 \mathrm{nM}$ group and 13.9 months in the $>2.7 \mathrm{nM}$ group (Figure 2D). In summary, high mesothelin levels were non-significantly associated with shorter OS when assessed as both continuous and categorical variables.

\section{Response rate}

To assess if mesothelin predicts for response to treatment, 18 patients whose sample was taken prior to chemotherapy were analysed. No patients had a complete response (CR), 5 patients (28\%) had a partial response (PR), 11 patients $(61 \%)$ had stable disease (SD) and 2 patients (11\%) had progressive disease (PD). This gives an overall response rate $(\mathrm{CR}+\mathrm{PR})$ of $28 \%$ and a disease stabilisation rate $(C R+P R+S D)$ of $89 \%$. In the $P D$ group the median mesothelin level was 10.0 (7.1-12.9), in the PR group 8.1 (2.9-23.8) and in the SD group $2.2(0.3-10.3)$. Paired comparisons between the response groups found no significant differences in pre-chemotherapy mesothelin levels (Figure 3).

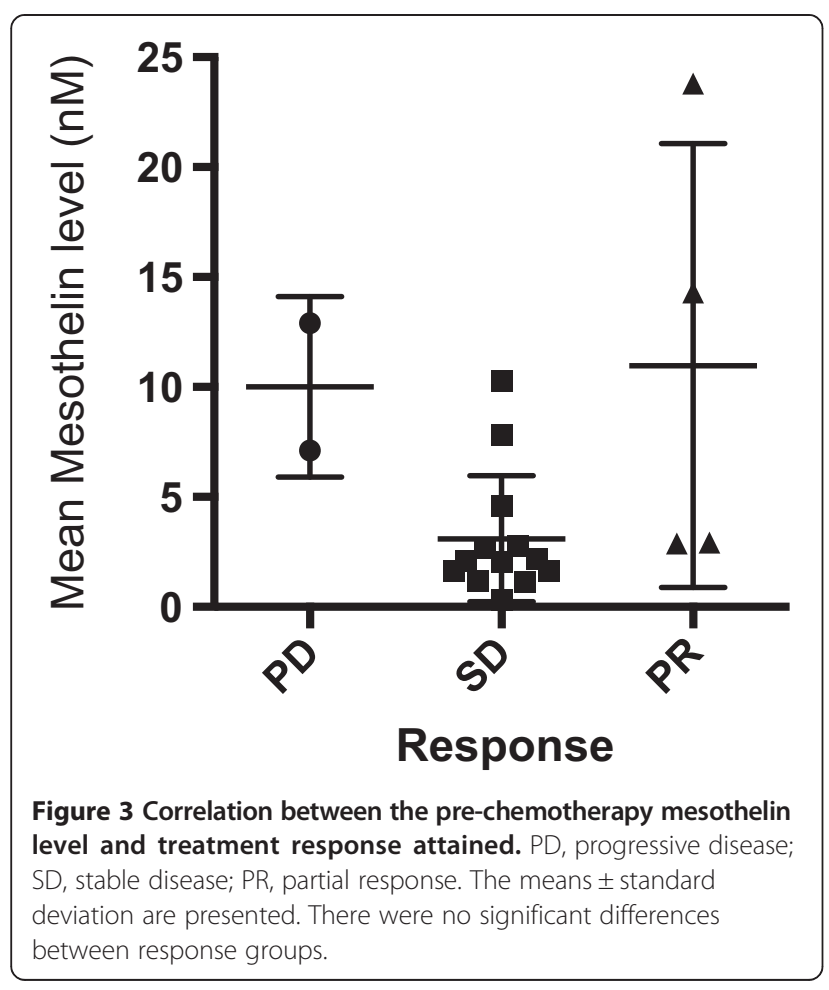

\section{Discussion}

We report the use of serum mesothelin in the assessment of patients with malignant mesothelioma in routine practice. We have demonstrated an improvement in PFS in association with lower mesothelin levels when assessed as a continuous variable and a non-significant improvement in PFS with lower mesothelin levels when assessed as a categorical variable. Lower than median mesothelin levels were also associated with a better OS, which did not reach statistical significance.

The high patient accrual rate and absence of technical failures of mesothelin assessment combined with the clinically meaningful outcome measures suggest that random mesothelin is both feasible and useful for routine management of mesothelioma patients. The mean age of patients in this study was higher than our institution historical data of patients with MM treated with chemotherapy [26] and from RCT data (69 years vs 63 years) [27], although performance status was similar. Despite this older patient population, and in some cases previous lines of chemotherapy, the PFS (7.0 vs 6.1 months) and OS (15.4 vs 12.8 months) were higher than trial data for first-line chemotherapy [28]. Furthermore, it must also be noted that our definition of PFS and OS for the purposes of this study were defined from the time of mesothelin sampling to progression and/or death, respectively, and therefore potentially underestimates the true OS, PFS and differences between the studies. The improved survival in our study compared to historical controls, likely reflects a higher proportion of female patients (32\% vs $20 \%$ ) and epithelioid histology (87\% compared to $67 \%$ ), both of which are recognised to carry a better prognosis [10].

The role of mesothelin as a biomarker has been extensively studied over recent years. A number of groups have used similar techniques to demonstrate a relationship between high mesothelin levels and survival (Table 2). We have been able to confirm that these previous results are applicable to routine clinical practice and would therefore support the use of this test in this everyday clinical setting. We were unable to demonstrate any correlation between the mesothelin level and the response to chemotherapy in the 18 patients that had a pre-chemotherapy serum mesothelin level however this study was underpowered to detect such a difference. Likely to be of much greater importance is the longitudinal measurement of serum mesothelin in patients receiving treatment. A decrease in mesothelin level has already been demonstrated in patients with MM receiving cytotoxic chemotherapy [24,25], and could become more significant still with the advent of mesothelin targeted immunotherapies. Anti-mesothelin strategies that are in early phase clinical testing include chimeric monoclonal antibodies [29], mesothelin antibodydrug conjugates [30], anti-mesothelin vaccines [31] and autologous transfer of T-cells transduced with chimeric 
Table 2 Studies of mesothelin as a prognostic biomarker

\begin{tabular}{|c|c|c|c|c|c|c|c|}
\hline Reference & $n$ & Males (\%) & Median age & Receiving CT (\%) & ORR (\%) & OS (months) & PFS (months) \\
\hline \multirow[t]{3}{*}{ Grigoriu et al. 2007 [13] } & 96 & 81 & 65 & 85 & NR & $m>3.5=7.0$ & NR \\
\hline & & & & & & $m \leq 3.5=19.0$ & \\
\hline & & & & & & $P=0.003$ & \\
\hline \multirow[t]{3}{*}{ Cristaudo et al. 2007 [34] } & 107 & 83.2 & 69 & NR & NR & $m>1=9.8$ & NR \\
\hline & & & & & & $m \leq 1=21.5$ & \\
\hline & & & & & & $P<0.001$ & \\
\hline \multirow[t]{3}{*}{ Creaney et al. 2011 [25] } & 97 & 89 & 66 & 69 & & $m<1=20.3$ & NR \\
\hline & & & & & & $m>5=12.5$ & \\
\hline & & & & & & $p=0.01$ & \\
\hline \multirow[t]{3}{*}{ Mori et al. 2013 [35] } & 26 & 21 & 5 & 26 & 19.2 & $m<0.469^{*}=26.6$ & NR \\
\hline & & & & & & $m>0.469^{*}=10.3$ & \\
\hline & & & & & & $p=0.027$ & \\
\hline \multirow[t]{4}{*}{ This study } & 53 & 68 & 69 & $57^{* *}$ & $m>2.7=26$ & $m>2.7=11.3$ & $m>2.7=5.1$ \\
\hline & & & & & $m \leq 2.7=0$ & $m \leq 2.7=17.2$ & $m \leq 2.7=8.0$ \\
\hline & & & & & & & $P=0.059^{\dagger}$ \\
\hline & & & & & & $P=0.088$ & \\
\hline
\end{tabular}

$n=$ number patients; ORR, overall response rate; OS, median overall survival; PFS, mean progression free survival; NR, not reported; CT, chemotherapy; m, mesothelin level in $\mathrm{nmol} / \mathrm{L}$

*This study used the median mesothelin index, calculated by Log2 (mesothelin level after 2 courses of chemotherapy level/mesothelin level prior to chemotherapy). Assay specifically detected N-terminal $31 \mathrm{kDa}$ fragment.

**18 patients (34\%) had a pre-chemotherapy mesothelin level and are therefore included in the response analysis.

${ }^{+}$If the PFS is analysed as a continuous variable for every unit increase the there is a HR of $1.03, p=0.013$.

antigen (mesothelin) receptors [32,33]. It is possible therefore, that pre-treatment serum mesothelin levels will serve as a biomarker predictive of anti-mesothelin treatment response and that longitudinal assessment will be a measure of treatment efficacy.

We have performed a small single institution exploratory study on the utility of serum mesothelin measurement in routine clinical practice and the findings broadly support the data from several previously published small prospective studies. Future, larger prospective studies are needed to validate the results presented here, and could be integrated with trials of mesothelin-targeted immunotherapy in mesothelioma. Additionally future studies must account for covariates, such as renal function, as subsequent to the design of our study, renal impairment was shown to lead to elevated mesothelin levels, which could reduce the accuracy of this assessment [36].

\section{Conclusions}

In summary, our data suggests that serum mesothelin assessment is a feasible and useful test for prognostication in mesothelioma in a routine clinical setting. Single measurements of mesothelin are however of limited clinical benefit. We advocate the validation of mesothelin testing as an adjunct to chemotherapy and immunotherapies in future research protocols.

\section{Consent}

Patient consent was not required as the study was submitted and approved as a Service Evaluation by the Royal Marsden Hospital's Audit Committee.

\section{Competing interests}

The authors declare that they have no competing interests.

\section{Authors' contributions}

SP designed the study. IJ performed the serum mesothelin assays. RG participated in the design of the study and performed the statistical analysis. SG, ML, BA, AN, JS, KP, MO, JB and SP were involved in the patients' examination, treatment, observation and serum sample collection, including follow-up. SG, ML and SP participated in writing the manuscript. All authors read and approved the final manuscript.

\section{Acknowledgements}

We acknowledge NHS funding to the NIHR Biomedical Research Centre.

Received: 9 December 2013 Accepted: 10 September 2014

Published: 17 September 2014

\section{References}

1. Hodgson JT, McElvenny DM, Darnton AJ, Price MJ, Peto J: The expected burden of mesothelioma mortality in Great Britain from 2002 to 2050. Br J Cancer 2005, 92(3):587-593.

2. Robinson BW, Lake RA: Advances in malignant mesothelioma. $N$ Engl J Med 2005, 353(15):1591-1603

3. Burt BM, Bader A, Winter D, Rodig SJ, Bueno R, Sugarbaker DJ: Expression of interleukin-4 receptor alpha in human pleural mesothelioma is associated with poor survival and promotion of tumor inflammation. Clin Cancer Res 2012, 18(6):1568-1577. 
4. Levallet $G$, Vaisse-Lesteven $M$, Le Stang N, Ilg AG, Brochard P, Astoul P, Pairon JC, Bergot E, Zalcman G, Galateau-Salle F: Plasma cell membrane localization of c-MET predicts longer survival in patients with malignant mesothelioma: a series of 157 cases from the MESOPATH Group. J Thorac Oncol 2012, 7(3):599-606

5. Kao SC, Armstrong N, Condon B, Griggs K, McCaughan B, Maltby S, Wilson A, Henderson DW, Klebe S: Aquaporin 1 is an independent prognostic factor in pleural malignant mesothelioma. Cancer 2012, 118(11):2952-2961.

6. Kao SC, Klebe S, Henderson DW, Reid G, Chatfield M, Armstrong NJ, Yan TD, Vardy J, Clarke S, van Zandwijk N, McCaughan B: Low calretinin expression and high neutrophil-to-lymphocyte ratio are poor prognostic factors in patients with malignant mesothelioma undergoing extrapleural pneumonectomy. J Thorac Oncol 2011, 6(11):1923-1929.

7. Baldi A, Mottolese M, Vincenzi B, Campioni M, Mellone P, Di Marino M, di Crescenzo VG, Visca P, Menegozzo S, Spugnini EP, Citro G, Ceribelli A, Mirri A, Chein J, Shridhar V, Ehrmann M, Santini M, Facciolo F: The serine protease $\mathrm{HtrA} 1$ is a novel prognostic factor for human mesothelioma. Pharmacogenomics 2008, 9(8):1069-1077.

8. Plathow C, Klopp M, Thieke C, Herth F, Thomas A, Schmaehl A, Zuna I, Kauczor HU: Therapy response in malignant pleural mesothelioma-role of MRI using RECIST, modified RECIST and volumetric approaches in comparison with CT. Eur Radio/ 2008, 18(8):1635-1643.

9. Byrne MJ, Nowak AK: Modified RECIST criteria for assessment of response in malignant pleural mesothelioma. Ann Oncol 2004, 15(2):257-260.

10. Steele JP, Klabatsa A, Fennell DA, Pallaska A, Sheaff MT, Evans MT, Shamash J, Rudd RM: Prognostic factors in mesothelioma. Lung Cancer 2005, 49(Suppl 1):S49-S52.

11. Ghanim B, Hoda MA, Winter MP, Klikovits T, Alimohammadi A, Hegedus B, Dome B, Grusch M, Arns M, Schenk P, Pohl W, Zielinski C, Filipits M, Klepetko W, Berger W: Pretreatment serum C-reactive protein levels predict benefit from multimodality treatment including radical surgery in malignant pleural mesothelioma: a retrospective multicenter analysis. Ann Surg 2012, 256(2):357-362.

12. Herndon JE, Green MR, Chahinian AP, Corson JM, Suzuki Y, Vogelzang NJ: Factors predictive of survival among 337 patients with mesothelioma treated between 1984 and 1994 by the Cancer and Leukemia Group B. Chest 1998, 113(3):723-731.

13. Grigoriu BD, Scherpereel A, Devos P, Chahine B, Letourneux M, Lebailly $P$, Gregoire M, Porte H, Copin MC, Lassalle P: Utility of osteopontin and serum mesothelin in malignant pleural mesothelioma diagnosis and prognosis assessment. Clin Cancer Res 2007, 13(10):2928-2935.

14. Pass HI, Levin SM, Harbut MR, Melamed J, Chiriboga L, Donington J, Huflejt M, Carbone M, Chia D, Goodglick L, Goodman GE, Thornquist MD, Liu G, de Perrot M, Tsao MS, Goparaju C: Fibulin-3 as a blood and effusion biomarker for pleural mesothelioma. N Engl J Med 2012, 367(15):1417-1427.

15. Cristaudo A, Foddis R, Vivaldi A, Guglielmi G, Dipalma N, Filiberti R, Neri M, Ceppi M, Paganuzzi M, Ivaldi GP, Mencoboni M, Canessa PA, Ambrosino N, Chella A, Mutti L, Puntoni R: Clinical significance of serum mesothelin in patients with mesothelioma and lung cancer. Clin Cancer Res 2007, 13(17):5076-5081.

16. Beyer HL, Geschwindt RD, Glover CL, Tran L, Hellstrom I, Hellstrom KE, Miller MC, Verch T, Allard WJ, Pass HI, Sardesai NY: MESOMARK: a potential test for malignant pleural mesothelioma. Clin Chem 2007, 53(4):666-672.

17. Pass HI, Wali A, Tang N, Ivanova A, Ivanov S, Harbut M, Carbone M, Allard J. Soluble mesothelin-related peptide level elevation in mesothelioma serum and pleural effusions. Ann Thorac Surg 2008, 85(1):265-272. discussion 272.

18. Pantazopoulos I, Boura P, Xanthos T, Syrigos K: Effectiveness of mesothelin family proteins and osteopontin for malignant mesothelioma. Eur Respir $J$ 2013, 41(3):706-715

19. Wang K, Bodempudi V, Liu Z, Borrego-Diaz E, Yamoutpoor F, Meyer A, Woo RA, Pan W, Dudek AZ, Olyaee MS, Esfandyari T, Farassati F: Inhibition of mesothelin as a novel strategy for targeting cancer cells. PLoS One 2012, 7(4):e33214.

20. Uehara N, Matsuoka Y, Tsubura A: Mesothelin promotes anchorage-independent growth and prevents anoikis via extracellular signal-regulated kinase signaling pathway in human breast cancer cells. Mol Cancer Res 2008, 6(2):186-193.

21. Kelly RJ, Sharon E, Pastan I, Hassan R: Mesothelin-targeted agents in clinical trials and in preclinical development. Mol Cancer Ther 2012, 11(3):517-525.
22. Wheatley-Price $P$, Yang B, Patsios D, Patel D, Ma C, Xu W, Leighl N, Feld R, Cho BC, O'Sullivan B, Roberts H, Tsao MS, Tammemagi M, Anraku M, Chen Z, de Perrot M, Liu G: Soluble mesothelin-related Peptide and osteopontin as markers of response in malignant mesothelioma. J Clin Oncol 2010, 28(20):3316-3322.

23. Creaney J, Christansen H, Lake R, Musk AB, de Klerk N, Robinson BW: Soluble mesothelin related protein in mesothelioma. J Thorac Oncol 2006, 1(2):172-174.

24. Grigoriu BD, Chahine B, Vachani A, Gey T, Conti M, Sterman DH, Marchandise G, Porte H, Albelda SM, Scherpereel A: Kinetics of soluble mesothelin in patients with malignant pleural mesothelioma during treatment. Am J Respir Crit Care Med 2009, 179(10):950-954.

25. Creaney J, Francis RJ, Dick IM, Musk AW, Robinson BW, Byrne MJ, Nowak AK: Serum soluble mesothelin concentrations in malignant pleural mesothelioma: relationship to tumor volume, clinical stage and changes in tumor burden. Clin Cancer Res 2011, 17(5):1181-1189.

26. Middleton GW, Smith IE, O'Brien ME, Norton A, Hickish T, Priest $K$, Spencer L, Ashley S: Good symptom relief with palliative MVP (mitomycin-C, vinblastine and cisplatin) chemotherapy in malignant mesothelioma. Ann Oncol 1998, 9(3):269-273.

27. Vogelzang NJ, Rusthoven JJ, Symanowski J, Denham C, Kaukel E, Ruffie P, Gatzemeier U, Boyer M, Emri S, Manegold C, Niyikiza C, Paoletti P: Phase III study of pemetrexed in combination with cisplatin versus cisplatin alone in patients with malignant pleural mesothelioma. J Clin Oncol 2003, 21(14):2636-2644.

28. Vogelzang N, Symanowski J, Rusthoven J, Manegold C, Boyer M, Nguyen B, Paoletti P: Long-term survival update from the randomized phase III study of pemetrexed plus cisplatin in patients with malignant pleural mesothelioma (MPM). Lung Cancer 2005, 49(2):S230-S231.

29. Hassan R, Cohen SJ, Phillips M, Pastan I, Sharon E, Kelly RJ, Schweizer C, Weil S, Laheru D: Phase I clinical trial of the chimeric anti-mesothelin monoclonal antibody MORAb-009 in patients with mesothelin-expressing cancers. Clin Cancer Res 2010, 16(24):6132-6138.

30. Rao C, Huber M, Vemuri K, Zhang Q, Chen B, Phillips J, Greenbaum M, Sung J, Derwin D, Passmore D, Vangipuram R, Terrett J, Deshpande S, Cardarelli P, Blanset D, Gangwar S: Abstract \#3235: Efficacy and toxicity of an anti-mesothelin antibody drug conjugate. Proc 100th Annu Meet Am Assoc Canc Res 2009, 2:3235.

31. Le DT, Brockstedt DG, Nir-Paz R, Hampl J, Mathur S, Nemunaitis J, Sterman DH, Hassan R, Lutz E, Moyer B, Giedlin M, Louis JL, Sugar EA, Pons A, Cox AL, Levine J, Murphy AL, Illei P, Dubensky TW Jr, Eiden JE, Jaffee EM, Laheru AD: A live-attenuated Listeria vaccine (ANZ-100) and a live-attenuated Listeria vaccine expressing mesothelin (CRS-207) for advanced cancers: phase I studies of safety and immune induction. Clin Cancer Res 2012, 18(3):858-868.

32. Colovos C, Villena-Vargas J, Adusumilli PS: Safety and stability of retrovirally transduced chimeric antigen receptor T cells. Immunotherapy 2012, 4(9):899-902.

33. Moon EK, Carpenito C, Sun J, Wang LC, Kapoor V, Predina J, Powell DJ Jr, Riley $J$, June $\mathrm{CH}$, Albelda SM: Expression of a functional CCR2 receptor enhances tumor localization and tumor eradication by retargeted human $T$ cells expressing a mesothelin-specific chimeric antibody receptor. Clin Cancer Res 2011, 17(14):4719-4730.

34. Cristaudo A, Bonotti A, Simonini S, Vivaldi A, Guglielmi G, Ambrosino N, Chella A, Lucchi M, Mussi A, Foddis R: Combined serum mesothelin and plasma osteopontin measurements in malignant pleural mesothelioma. J Thorac Oncol 2011, 6(9):1587-1593.

35. Mori T, Tajima K, Hirama M, Sato T, Kido K, Iwakami S, Sasaki S, Iwase A Shiomi K, Maeda M, Hino O, Takahashi K: The N-ERC index is a novel monitoring and prognostic marker for advanced malignant pleural mesothelioma. J Thorac Dis 2013, 5(2):145-148.

36. Boudville N, Paul R, Robinson BW, Creaney J: Mesothelin and kidney function-analysis of relationship and implications for mesothelioma screening. Lung Cancer 2011, 73(3):320-324.

doi:10.1186/1471-2407-14-674

Cite this article as: Linch et al:: A serum mesothelin level is a prognostic indicator for patients with malignant mesothelioma in routine clinical practice. BMC Cancer 2014 14:674. 